\title{
Auxerre, la cathédrale Saint-Étienne
}

\section{Christian Sapin}

\section{(2) OpenEdition}

\section{Journals}

\section{Édition électronique}

URL : https://journals.openedition.org/cem/644

DOI : 10.4000/cem.644

ISSN : 1954-3093

\section{Éditeur}

Centre d'études médiévales Saint-Germain d'Auxerre

\section{Édition imprimée}

Date de publication : 15 août 2005

ISSN : 1623-5770

\section{Référence électronique}

Christian Sapin, « Auxerre, la cathédrale Saint-Étienne », Bulletin du centre d'études médiévales d'Auxerre | BUCEMA [En ligne], 9 | 2005, mis en ligne le 13 octobre 2006, consulté le 22 septembre 2022. URL http://journals.openedition.org/cem/644; DOI : https://doi.org/10.4000/cem.644

Ce document a été généré automatiquement le 22 septembre 2022.

\section{(c) (i) (2)(2)}

Creative Commons - Attribution - Pas d'Utilisation Commerciale - Partage dans les Mêmes Conditions 4.0 International - CC BY-NC-SA 4.0

https://creativecommons.org/licenses/by-nc-sa/4.0/ 


\title{
Auxerre, la cathédrale Saint-Étienne
}

\author{
Christian Sapin
}

1 Depuis trois ans, la crypte de la cathédrale qui, rappelons-le, constitue une des plus grandes cryptes romane de France construite dans la première moitié du XIe siècle, est l'objet de recherches archéologiques programmées de la part du Centre d'études médiévales. Il ne s'agit pas seulement de travaux au sol ${ }^{1}$ mais également d'études à partir des élévations. C'est ainsi qu'en 2004, l'examen méthodique des maçonneries (type de pierre, traces de taille, mortier) conservées dans l'angle sud-ouest de la grande salle a confirmé la cohérence du premier état initial roman, ainsi que les modifications d'ouverture et les transformations résultant des restaurations du XIXe siècle. Dans l'ouverture sud de la salle centrale, en démontant la maçonnerie en glacis créée au XIXe siècle, ont été plus précisément retrouvés, de la même façon qu'au nord, les traces des deux états initiaux. On peut désormais distinguer de ce côté la reprise de l'arcade murale en ouverture avec l'escalier ainsi que des modifications avec l'installation de portes. La connaissance des mortiers de scellement autorise à situer celles-ci dans la troisième phase d'aménagement que l'on peut placer au XIIe siècle, avant la construction des piliers gothiques. C'est aussi lors de cette période intermédiaire que l'on peut situer des traces d'encastrement visibles dans les piliers, transformant la première travée d'accès sud en sas, sans qu'on puisse dire si ces travaux sont dus à une volonté de modifier le circuit pour des raisons liturgiques ou en fonction de la préparation du chantier du chœur. En tout état de cause, ces informations renforcent les hypothèses quant à l'importance des accès et de leur évolution dans la compréhension générale de la crypte romane.

D'autres indications sur l'occupation antérieure à l'époque romane ont été recueillies dans la fouille de l'ouverture sud après enlèvement du glacis. La stratigraphie montre plusieurs niveaux plus ou moins damés qui sont contemporains des niveaux d'occupation du haut Moyen Âge observés en 2003 tant dans l'ouverture au nord qu'au sud de la salle. Aucune structure nouvelle n'est apparue; cela concorde avec le plan d'ouverture d'abside proposé l'an dernier dans la restitution².

Parallèlement, une partie de l'équipe du CEM en collaboration avec les collègues de l'université de Stuttgart ont précédé ou suivent de près les travaux de restauration 
(voir ci-après "Suivis de travaux aux abords et sur des édifices religieux de l'Yonne" par S. Aumard).

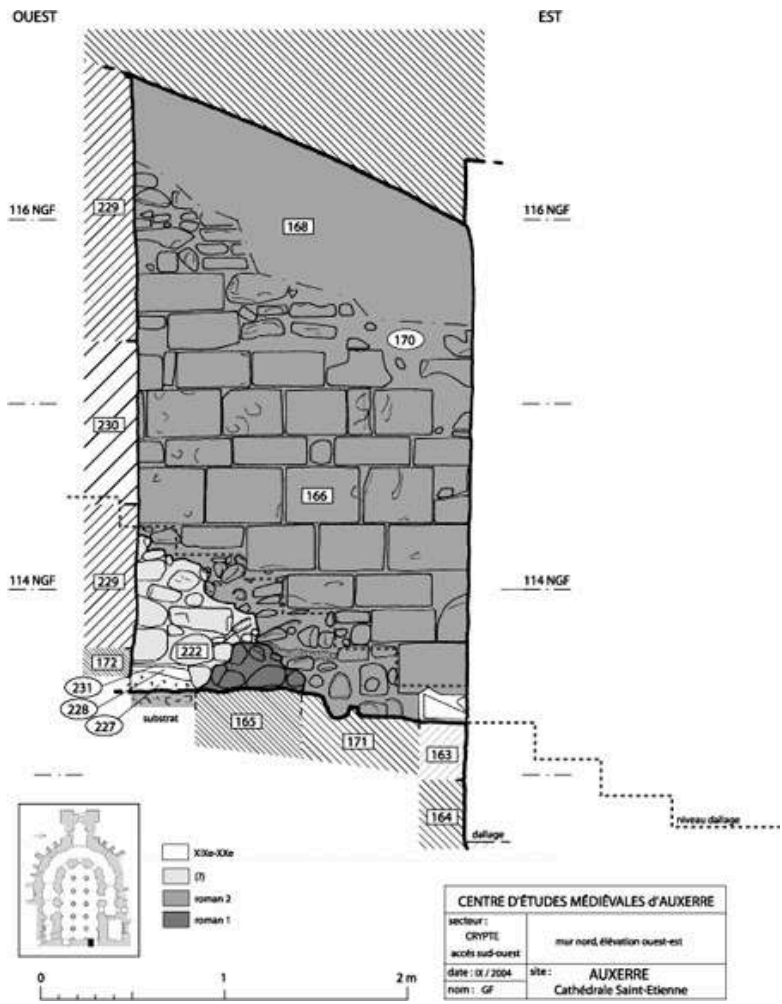

Auxerre, cathédrale Saint-Étienne. Crypte. Salle centrale. Mur ouest, ouverture sud, relevé de l'élévation nord montrant les traces de l'escalier arraché (CEM, 2004, G. Fèvre).

\section{NOTES DE FIN}

1. Voir Études \& Travaux, 2003-2004, CEM 8, p. 15-16.

2. ID., p. 16.

\section{INDEX}

\section{Index géographique : France/Auxerre}

Mots-clés : cathédrale, Etienne (saint), Saint-Etienne d'Auxerre 